\title{
Systemic interferon alpha-2b increases the cure rate in laser treated patients with multiple persistent genital warts: a placebo-controlled study
}

Carsten Sand Petersen, Peter Bjerring, John Larsen, Jan Blaakær, Hans Hagdrup, Ellis From, L Obergaard

\begin{abstract}
Systemic treatment modalities for eradication of multiple therapy resistant genital warts are so far not available. In this study laser treated patients with multiple genital warts received postoperatively either interferon alpha-2b subcutaneously (s.c.) $5 \times 10^{6}$ IU or matching placebo three times weekly for four weeks. At the conclusion of the study, 6-8 weeks after discontinuation of therapy, a significantly higher cure rate was found in the group of interferon-treated patients (14 of $27(52 \%)$ patients cured) than among placebo treated patients (5 of $22(23 \%)$ patients cured) $(p<0.05)$. The side effects of fever, chills, myalgia, headache and leukopenia occurred more commonly in the interferon treated group than in the placebo group. However, only three of 32 patients discontinued interferon therapy because of side effects. We conclude that the addition of s.c. administered interferon alpha-2b to laser treated patients with chronic therapy resistant genital warts is fairly well tolerated and that it significantly enhances the chance of eliminating the disease.
\end{abstract}

\section{Introduction}

The optimal treatment modality has not been established in patients with recalcitrant multiple genital warts. A variety of ablative treatments for podophyllin resistant genital warts are available, including cryosurgery, electrocautery and laser therapy.

Department of Dermatology and Venereology, Bispebjerg Hospital, University of Copenhagen Carsten Sand Petersen, John Larsen, L Obergaard

Department of Dermatology and Venereology, Marselisborg Hospital, University of Aarhus

Peter Bjerring, Ellis From

Department of Dermatology and Venereology, Odense Hospital, University of Odense

Hans Hagdrup

Department of Gynecology, Righospitalet, University of Copenhagen, Denmark

Jan Blaakær
Recently both recombinant alpha interferons and lymphoblastoid interferon intralesionally injected have shown to be effective in eradicating small numbers of warts. ${ }^{1-2}$ Systemic administration of alpha interferons and lymphoblastoid interferon as monotherapy has also demonstrated an effect on human papillomavirus (HPV)-induced lesions, ${ }^{3-5}$ an effect that in one study was comparable to electrocautery. ${ }^{6}$

The current therapy of choice for multiple chronic genital warts in Danish dermatologic departments is laser therapy, but it is our experience that the cure rate is disappointingly low for this group of patients. Placebo controlled trials combining laser therapy with systemic administration of alpha interferon in these patients has to our knowledge not been published.

In this placebo controlled study we show that laser treated patients with otherwise therapy resistant genital warts have a higher cure rate, if the surgical procedure is followed by a course of subcutaneous (s.c.) interferon alpha- $2 b$ injections.

\section{Patients and methods}

The study was conducted, and approved by the local ethics committees, at the Dermato-Venereological centres in Copenhagen, Aarhus and Odense and at one gynaecologic centre in Copenhagen, which enrolled 14, 24, 10 and 7 patients, respectively. The patients were all referred for laser therapy and all had podophyllin resistant genital warts. Sixty-nine per cent of the study population had had warts for more than 12 months. The majority of the patients had previously been treated with electrocautery, cryotherapy or laser (table 1). A semiquantitative evaluation prior to treatment showed that $84 \%$ of the patients had more than five lesions (table 1). Before entering the trial all patients were offered HIV antibody testing to exclude acquired immunodeficiency. Twenty-eight interferon recipients and 21 placebo recipients that underwent testing were all found to be antibody negative.

$\mathrm{A} \mathrm{CO}_{2}$-laser (Sharplan 733) with an effect of 5-20 watt was used to evaporate the genital warts in Copenhagen. In Aarhus and Odense operations were 
Table 1 Demographic data on the patients

\begin{tabular}{|c|c|c|}
\hline \multirow[b]{2}{*}{ Characteristic } & \multicolumn{2}{|c|}{ Study group } \\
\hline & $\begin{array}{l}\text { Interferon } \\
n=32\end{array}$ & $\begin{array}{l}\text { Placebo } \\
n=23\end{array}$ \\
\hline Mean age (yr) & 27 & 23 \\
\hline Males & 22 & 14 \\
\hline Females & 10 & 9 \\
\hline \multicolumn{3}{|l|}{ Previous therapy } \\
\hline podophyllin & 32 & 23 \\
\hline surgery & 17 & 17 \\
\hline cryotherapy & 5 & 3 \\
\hline \multicolumn{3}{|l|}{ No of warts per patient } \\
\hline $0-5$ & 6 & 3 \\
\hline $6-10$ & 10 & 8 \\
\hline $11-50$ & 14 & 9 \\
\hline$>50$ & 2 & 3 \\
\hline \multicolumn{3}{|l|}{ Location of warts } \\
\hline penile & 18 & 13 \\
\hline vulvar & 8 & 10 \\
\hline peri/intraanal & 13 & 11 \\
\hline vagina/portio & 3 & 3 \\
\hline \multicolumn{3}{|c|}{ Duration of warts (months) } \\
\hline $3-6$ & 2 & 1 \\
\hline $7-12$ & 8 & 6 \\
\hline$>12$ & 22 & 16 \\
\hline \multicolumn{3}{|l|}{ Actual treatment } \\
\hline $\mathrm{CO}_{2}$-laser & 10 & 7 \\
\hline Argon-laser & 13 & 11 \\
\hline Copper vapour laser & 4 & 5 \\
\hline
\end{tabular}

performed with an Argon-laser (Cooper Medical, USA) with an effect of $1.5-2.0$ watt at 488 and $515 \mathrm{~nm}$ and a Copper vapour laser (PBI $10 \mathrm{Cu}$, Denmark), with an effect of 4.5 watt at 510 and $578 \mathrm{~nm}$, respectively. The patients were randomly assigned to receive $5 \times 10^{6} \mathrm{I}$.U. of interferon alpha$2 \mathrm{~b}$ (Intron A) or placebo s.c. in the gluteal region within 72 hours after the laser operation. Injections were given on three alternate days per week for 4 weeks. All patients received $1 \mathrm{~g}$ of acetaminophen at the time of injection and systemic symptoms at the day of injection could be treated with additional 1-2 $\mathrm{g}$ of acetaminophen.

Evaluation for safety, by questioning the patients, was made at each of the 12 visits for injections. Patients were also monitored once weekly in the four treatment weeks with standard laboratory tests, including blood cell count with differential and platelet counts, aspartate aminotransferase, alkaline phosphatase and total bilirubin.

Evaluation for efficacy (cured/not cured) was based on a clinical examination of patients at the end
Table 3 The response to s.c. administration of interferon alpha- $2 b$ according to the pretreatment number of warts

\begin{tabular}{llc}
\hline \multirow{2}{*}{ No of warts } & \multicolumn{2}{c}{ No of interferon recipients } \\
\cline { 2 - 3 } & Cured & Recurrences \\
\hline$\leqslant 10$ & $10(77 \%)^{\star}$ & 3 \\
$\geqslant 11$ & $4(29 \%)^{\star}$ & 10 \\
\hline${ }^{\star} \mathrm{p}<0.02$ & &
\end{tabular}

of the injection period and 6 and 8 weeks after completion of the interferon/placebo regimens.

We compared the two treatment groups at base line using Student's $t$ test or Fishers's exact test. The chi square test was used in the efficacy analyses.

\section{Results}

A total of 55 patients with condylomata acuminata were enrolled in the study; 32 received interferon and 23 placebo. Six patients were excluded from efficacy analyses either because of adverse effects (two interferon recipients), or drop-out without known reasons (two interferon and one placebo recipients) or due to insufficient clinical effect according to patients own evaluation (one interferon recipient). Thus 27 interferon treated and 22 placebo treated patients were included in the efficacy analysis.

Analysis of the demographics of the two groups indicated no significant differences with respect to any variable (table 1 ).

The maximal differences in clinical response between the interferon and the placebo groups occurred 6 and 8 weeks after completion of the injection therapy (table 2). At that time 14 of 27 interferon recipients $(52 \%)$ and five of 22 placebo recipients $(23 \%)$ had no detectable warts at the clinical examination $(\mathrm{p}<0.05)$. Of the 14 patients who had received interferon and were followed after the study period, two had a relapse and 10 patients were free of warts after 24 weeks of follow-up. Two of the 14 patients were lost to follow-up.

The response to interferon appeared to be independent of the sex of the patient, previous therapy, wart age and location of warts. However, interferon responders had compared with non-

Table 2 Evaluation of efficacy of interferon alpha-2b treatment of patients with recalcitrant genital warts

\begin{tabular}{|c|c|c|c|c|}
\hline \multirow{2}{*}{$\begin{array}{l}\text { Time after } \\
\text { laser therapy } \\
\text { (weeks) }\end{array}$} & \multicolumn{2}{|c|}{ Placebo $n=22$} & \multicolumn{2}{|c|}{ Interferon $n=27$} \\
\hline & Cured & Recurrence & Cured & Recurrence \\
\hline $\begin{array}{r}4 \\
10 \\
12\end{array}$ & $\begin{array}{l}7(32 \%) \\
5(23 \%)^{\star} \\
5(23 \%)^{\star}\end{array}$ & $\begin{array}{l}15 \\
17 \\
17\end{array}$ & $\begin{array}{l}13(48 \%) \\
14(52 \%)^{\star} \\
14(52 \%)^{\star}\end{array}$ & $\begin{array}{l}14 \\
13 \\
13\end{array}$ \\
\hline
\end{tabular}


Table 4 Adverse effects of therapy

\begin{tabular}{llc}
\hline & Interferon & Placebo \\
\cline { 2 - 3 } Effect & Percent of patients \\
\hline Constitutional symptoms & 56 & \\
Fever & 50 & 4 \\
Chills & 63 & 13 \\
Headache & 50 & 4 \\
Myalgias & 9 & - \\
Arthralgias & 22 & 22 \\
Fatigue & 13 & 4 \\
Vertigo & 3 & 4 \\
Dyspepsia & 9 & 13 \\
Local reactions at injection site & 28 & 9 \\
Leukopenia & 3 & - \\
Thrombocytopenia & & \\
\hline
\end{tabular}

responders significantly fewer warts at base line (table 3).

The percent of patients with observed adverse effects are shown in table 4 . Among the 55 patients considered in the safety assessments adverse effects were noted in 28 of 32 interferon recipients and in 11 of 23 placebo recipients. Two interferon treated patients discontinued therapy owing to the combination of fever, chills, myalgias and malaise. Generally, the influenza-like symptoms observed in the majority of interferon recipients were mostly present after the first and second injection and subsided gradually.

Analysis of blood samples obtained during therapy revealed abnormalities in white-cell and platelet counts. Nine patients, who received interferon, had leukopenia; six had white-cell counts of 3.2 to $3.9 \times 10^{3} / \mathrm{mm}^{3}$, whereas three had counts of 2.1 to $2.9 \times 10^{3} / \mathrm{mm}^{3}$. Thrombocytopenia was noted in one interferon treated patient $\left(126,000\right.$ cells $\left./ \mathrm{mm}^{3}\right)$. These abnormal values all returned to normal at the end of the study. None of the treated patients had abnormal liver-function tests. Two patients had one injection postponed for 3 days due to leukopenia.

\section{Discussion}

As compared with placebo recipients interferon alpha- $2 b$ recipients were shown to obtain a significantly increased cure rate 6 and 8 weeks after conclusion of 4 weeks of therapy. The therapeutic response was sustained as 71 and possibly as high as $86 \%$ of the interferon responders were still free of warts at the 24 week follow-up. Patients with 11 or more warts responded less favourably than patients with 10 or less warts. This is in full accordance with the results reported in a previous investigation of intralesionally injected interferon alpha- $2 b$, where patients with small wart areas responded more readily than patients with large wart areas. ${ }^{1}$

We do not know the optimal duration of the interferon therapy postoperatively. It is possible, however, that a more prolonged injection period would result in an even higher cure rate in analogy with the experience in patients with chronic active hepatitis B where s.c. injections of interferon alpha$2 \mathrm{~b} 5 \times 10^{6}$ I.U. three times weekly for 16 weeks are needed for elimination of the chronic infection in a significant proportion of the patients. ${ }^{7}$ Future doseresponse studies should evaluate this aspect.

The cure rate of $23 \%$ obtained in the placebo group was nearly identical to the $27 \%$ cure rate seen in Danish patients with chronic genital warts treated with $\mathrm{CO}_{2}$-laser. ${ }^{8}$

The beneficial effect of interferon demonstrated in our study is supported by the finding, in a recently published uncontrolled study ${ }^{9}$ that adjuvant systemic interferon alpha-2b $\left(3 \times 10^{6} \mathrm{I}\right.$.U. daily for 7 days) given to laser treated patients with refractory genital warts resulted in a high cure rate.

Owing to the multiple and discrete distribution of the warts, we have not performed a quantitative assessment of the total wart area before and after therapy. This approach has been used in studies evaluating the efficacy of intralesionally injected interferon alpha-2b into 1 to 3 warts, ${ }^{110}$ but although this would be optimal, practical reasons did not allow this procedure in our study. Treatment modalities using intraleşional or perilesional injection of interferon is in our opinion not a feasible way of treatment in patients with multiple disseminated lesions.

Systemic adverse reactions to interferon including fever, chills, headache, myalgia, and fatigue were usually mild and decreased in intensity during the four week treatment period suggesting that a tolerance to treatment developed. All side effects, including the decrease in white cell and platelet counts, are commonly associated with systemic interferon therapy.

The results of the present study indicate that a sufficiently high concentration of interferon is obtained in the HPV infected genital epithelium, and we consider the systemic administration of interferon alpha- $2 b$ to be a suitable way of potentiating the effect of laser therapy in otherwise therapy resistant patients.

Address for correspondence: Carsten Sand Petersen MD, Department of Dermatology, Rigshospitalet, Blegdamsvej 3, 2100 Copenhagen $\varnothing$, Denmark

1 Eron LJ, Judson F, Tucker S, et al. Interferon therapy for condylomata acuminata. $N$ Engl J Med 1986;315:1059-64.

2 Reichman RC, Oakes D, Bonnez W, et al. Treatment of condyloma acuminatum with three different interferons administered intralesionally. Ann Intern Med 1988;108:675-9.

3 Gross G, Ikenberg H, Roussaki A, et al. Systemic treatment of condylomata acuminata with recombinant interferon-alpha2a: low dose superior to high dose regimen. J Chemother 1986;32:537-41. 
4 Olsen É, Kelly FF, Vollmer RT, et al. Comparative study of systemic interferon alfa-N1 and isotretinoin in the treatment of resistant condylomata acuminata. J Am Acad Dermatol 1989;20:1023-30.

5 Zachariae H, Larsen PM, Søgaard PM. Recombinant interferon alpha-2a (Roferon-A) in a case of Buschke-Löwenstein giant condyloma. Dermatologica 1988;177:175-9.

6 Benedetti PP, Scambia G, Baiocchi G, et al. Randomized clinical trial comparing systemic interferon with diathermocoagulation in primary multiple and widespread anogenital condyloma. Obstet Gynecol 1989;74:393-7.

7 Perrillo RP, Schiff ER, Davis GL, et al. A randomized, controlled trial of interferon alfa- $2 \mathrm{~b}$ alone and after prednisone withdrawal for the treatment of chronic hepatitis B. N Engl J Med 1990;323:295-301.
8 Larsen J, Sand Petersen C. The patient with refractory genital warts in the STD-clinic. Treatment failure with $\mathrm{CO}_{2}$-laser. Dan Med Bull 1990;37:194-5.

9 Erpenbach K, Derschum W, Vietsch H. Adjuvant-systemische interferon-alpha $2 \mathrm{~b}$-behandlung bei therapieresistenten anogenitalen condylomata acuminata. Urologe 1990;29:43-5.

10 Vance JC, Bart BJ, Hansen RC, et al. Intralesional recombinant alpha-2 interferon for treatment of patients with condyloma acuminatum or verruca plantaris. Arch Dermatol 1986; 122:273-7.

Accepted 26 November 1990 